\title{
HUBUNGAN ANTARA HARGA, MEREK, THREAT EMOTION, DAN LOKASI PENJUALAN DENGAN LOYALITAS KONSUMEN YOGHURT MEMORY 84 DI KOTA SALATIGA
}

\author{
Firmanto $^{* 11}$, Bayu Nuswantara ${ }^{2)}$ \\ 1) Program Studi Agribinsis Fakultas Pertanian dan Bisnis Universitas Kristen Satya Wacana \\ 2) Fakultas Pertanian dan Bisnis Universitas Kristen Satya Wacana \\ *) E-mail Penulis Korespondensi: 522014035@student.uksw.edu
}

\begin{abstract}
ABSTRAK
Yoghurt Memory 84 merupakan susu hasil fermentasi yang diproduksi di Kota Salatiga. Sehubungan dengan perkembangan usaha yang semakin maju di era sekarang, loyalitas konsumen menjadi salah satu penentu keberlangsungan suatu usaha. Tujuan dari penelitian ini adalah untuk menganalisis hubungan harga, merek, threat emotion dan lokasi penjualan terhadap loyalitas konsumen Yoghurt Memory 84. Penelitian ini dilaksanakan pada bulan Mei sampai dengan bulan Juni tahun 2019. Penelitian ini menggunakan jenis penelitian deskriptif kuantitatif dengan metode survei. Teknik pengambilan sampel pada penelitian ini menggunakan insidental sampling. Jumlah responden yang diambil dalam penelitian ini sebanyak 50 orang konsumen Yoghurt Memory 84. Hasil penelitian menunjukkan bahwa harga (X1) memiliki tingkat hubungan sangat kuat terhadap loyalitas konsumen $(\mathrm{Y})$ dengan nilai korelasi 0,874 ; merek (X2) memiliki tingkat hubungan rendah terhadap loyalitas konsumen $(Y)$ dengan nilai korelasi 0,351 ; threat emotion $(X 3)$ memiliki tingkat hubungan sedang terhadap loyalitas konsumen $(Y)$ dengan nilai korelasi 0,595; dan lokasi penjualan (X4) memiliki tingkat hubungan kuat terhadap loyalitas konsumen (Y) nilai korelasi 0,793 . Semua variabel harga, merek, threat emotion, dan lokasi penjualan terbukti positif dan signifikan dengan loyalitas konsumen $(\mathrm{Y})$. Pengelola Yoghurt Memory 84 perlu memperhatikan variabel-variabel dalam penelitian ini, terutama harga dan lokasi penjualan untuk meningkatkan loyalitas konsumen.
\end{abstract}

Kata kunci: harga; merek; threat emotion; lokasi penjualan; loyalitas konsumen.

\section{PENDAHULUAN}

Banyak upaya dan inovasi yang dilakukan untuk mempertahankan umur simpan susu dengan sentuhan teknologi-teknologi moderen, sehingga susu mengalami difermentasi produk, salah satunya yaitu yoghurt. Yoghurt adalah suatu produk fermentasi yang melibatkan jasa mikroorganisme yaitu bakteri. Yoghurt terbentuk dari bakteri baik yang bermanfaat bagi kesehatan yang diperoleh dari susu segar dengan campuran Lactobacillus Bulgaricus dan Streptococcus Thermophilus. Ada beberapa macam yoghurt komersial dengan dibagi menjadi 3 kategori utama, yaitu: Plain/natural yoghurt (yoghurt tanpa penambahan bahan selain susu dan kultuer), fruit yoghurt (yoghurt yang ditambah bahu), dan flavoured yoghurt (yoghurt yang berflavour) (Tamime dan Robinson, 2007).

Keputusan pembelian produk adalah suatu tindakan atau perilaku konsumen yang melakukan pembelian atau transaksi (Kotler dan Amstrong, 2014). Banyak tindakan konsumen dalam mengambil keputusan menjadi salah satu penentu tercapai atau tindakan sesuatu tujuan perusahaan. Keputusan pembelian merupakan sikap seseorang untuk membeli atau menggunakan suatu produk baik berupa barang dan jasa yang telah diyakini 
akan memuaskan dirinya dan kesedian menanggung resiko yang mengkin ditimbulkan. Keputusan pembelian yang diambil oleh pembeli sebenarnya merupakan kumpulan dari sejumlah keputusan yang terorganisir (Aldi, 2012).

Dalam kehidupan berbisnis, harga merupakan slah satu faktor penting yang mempengaruhi pemasaran suatu produk. Tinggi rendahnya harga selalu menjadi perhatian utama para konsumen saat mereka mencari suatu produk. Sehingga harga yang ditawarkan menjadi bahan pertimbangan khusus, sebelum mereka memutuskan untuk membeli barang maupun menggunakan suatu jasa. Strategi penetapan harga sangat berpengaruh terhadap penjualan maupun pemasaran produk yang ditawarkan. Harga merupakan penentu profil sebuah perusahan mendapatkan laba dari selisih antara pendapatan dengan keseluruhan biaya yang ditimbulkan untuk produksi produk yang dihasilkan perusahan tersebut (Kotler dan Keller, 2009).

Perusahan harus memikirkan pelanggan dengan produk atau jasa yang ditawarkan perusahan untuk menemukan titik diferensiasi. Sebuah perusahan dapat menemukan cara untuk membedakan dirinya ditinjau dari aspek produk, pelayanan, personil dan merek yang merupakan komponen dari strategi diferensiasi, sedangkan diferensiasi itu sendiri merupakan bagian dari positioning. Diferensiasi ini dilakukan untuk membangunn positioning di benak pelanggan. Artinya sebuah produk atau merek harus mengkomunikasikan dirinya sebagai nomor satu yang dapat memberikan manfaat yang dibutuhkan dan dicari oleh pelanggan. Oleh karena itu variabel brand trust merupakan hal penting lainnya. Sebab dengan adanya kepercayaan konsumen terhadap sebuah merek tertentu maka akan membuat keputusan pembelian semakin kuat (Kotler dan Amstrong, 2014).

Dilain pihak, dinamika proses pengambilan keputusan konsumen tidak akan lepas dari kondisi emosinya bahkan di masa mendatang emosi konsumen akan memberikan dampak tersendiri pada hasil evaluasi atribut produk, dan lebih penting lagi adalah adanya peran kepercayaan yang diletakan oleh konsumen memenuhi kebutuhan. Dalam proses keputusan pembelian, proses dimulai dengan menilai tekanan tersebut sebagai hal positif atau negatif. Ketika konsumen menilai tekanan tersebut sebagai hal positif atau sesuai dengan tujuannya, maka yang muncul adalah challenge emotion yang ditujukan perasaan bersemangat, penuh harapan dan penuh percaya diri. Sementara ketika konsumen menilai tekanan tersebut negatif, maka yang timbul adalah threat emotion atau perasaan terancam. Perasaan terancam semacam ini akan menumbuhkan perasaan gelisah, takut dan apprehension. Tujuan utama dari pemasaran adalah mengintensifkan hubungan antara konsumen dengan merek dan komponen utama adalah kepercayaan. Tetapi kepercayaan (trust) adalah konsep yang sulit untuk di pahami (Hiscock, 2001). Maka dari itu threat emotion merupakan hal penting yang memegang peran terhadap keputusan pembelian konsumen. Akan tetapi keputusan pembelian tidak hanya berpedoman pada harga yang murah saja, tetapi pada kualitas pelayanan, lokasi usaha, kualitas produk yang ditawarkan, serta lingkungan usaha dan lain sebagainya juga mempengaruhi kepercayaan dalam keputusan pembelian (Yuliani, 2010).

Para pelaku bisnis baik yang bergerak di bidang produksi maupun jasa terdorong untuk menggeser orientasi usaha dari profit oriented menjadi loyalty, yaitu orientasi kepada loyalitas. Loyalitas konsumen berpengaruh terhadap kelangsungan hidup perusahaan, karena adanya penggunaan produk dan jasa yang di gunakan terus-menerus oleh pelanggan (Shafa dkk, 2016). Berbagai strategi dan cara untuk memuaskan kebutuhan konsumen dilakukan setiap perusahaan dengan harapan konsumen merasa puas dan akan melakukan pembelian ulang. Ketika seorang konsumen menjadi pelanggan yang setia karena merasa puas dan juga senang dengan produk atau pelayanan, maka konsumen tersebut tidak akan beralih ke produk lain. Penelitian ini bertujuan untuk menganalisis hubungan antara harga, merek, threat emotion dan lokasi penjualan dengan loyalitas konsumen. 


\section{METODE}

\section{Tempat Penelitian}

Penelitian ini berlokasi di Yoghurt Memory 84 Jl. Dipomenggolo, Pulutan, Sidorejo, Kota Salatiga, Jawa Tengah. Pemilihan lokasi penelitian secara sengaja (purposive) dengan pertimbangan di tempat tersebut memproduksi Yoghurt Memory 84.

\section{Metode Penelitian}

Penelitian ini merupakan penelitian deskriptif kuantitatif, dimana bertujuan untuk memberikan penjelasan atau menjabarkan, meringkas berbagai kondisi suatu keadaan atau fenomena yang terjadi di masyarakat yang menjadi objek penelitian berdasarakan apa yang terjadi (Sugiyono, 2013).

Metode yang digunakan dalam penelitian ini adalah metode survey. Metode survey digunakan untuk memperoleh data dari suatu tempat yaitu di Yoghurt Memory 84 tertentu, sebagai alat pengumpulan data peneliti melakukan perlakuan seperti mengedarkan kuesioner, wawancara pribadi, panel dan telpon untuk memperolah informasi.

\section{Tehnik Pengambilan Sampel}

Teknik pengambilan sampel pada penelitian ini menggunakan accidental sampling. Accidental sampling mengambil sampel secara aksidental (accidental) dengan mengambil kasus atau responden yang kebetulan ada atau tersedia di suatu tempat sesuai dengan konteks penelitian (Notoatmodjo, 2010). Accidental sampling adalah teknik penentuan sampel berdasarkan kebetulan, yaitu siapa saja yang secara kebetulan bertemu dengan peneliti dapat digunakan sebagai sampel bila dipandang orang yang kebetulan ditemui itu sesuai sebagai sumber data (Sugiyono, 2013). Jumlah sampel yang diambil dalam penelitian ini adalah sebanyak 50 orang responden yang kebetulan bertemu di Yoghurt Memory 84. Besaran sampel ditentukan dengan mengacu pada pendapat Roscoe (1982) yang dikutip oleh Sugiyono (2013), memberikan acuan umum untuk menentukan ukuran sampel yaitu jika dalam penelitian akan melakukan analisis dengan multivariate (korelasi atau regresi berganda), maka jumlah anggota minimal 10 kali dari jumlah variabel yang diteliti. Misalnya variabel penelitian 5 (independen + dependen), maka sampel sebesar = $10 \times(4+1)=50$ responden.

\section{Tehnik Pengumpulan Data}

Pengumpulan data dalam penelitian ini dilakukan secara primer dan sekunder. Data primer diperoleh secara langsung dari objek yang diteliti yang peneliti lakukan melalui: studi pustaka, observasi, dan dokumentasi.

Instrumen penelitian ini menggunakan kuesioner dengan skala pengukuran sikap, pendapat dan persepsi karyawan atau kelompok orang tentang fenomena sosial yang terjadi. Berikut merupakan komposisi pengukuran dengan mengunakan skala likert:
STS (sangat tidak setuju) : diberi skor 1
TS (tidak setuju) : diberi skor 2
$\mathrm{N}$ (netral) : diberi skor 3
$\mathrm{S}$ (setuju) : diberi skor 4
SS (sangat setuju) : diberi skor 5

Data sekunder diperoleh mengacu pada informasi yang dikumpulkan dari sumber yang ada. Data ini digunakan sebagai penguat data primer yang diperoleh dengan menggunakan studi literatur yang dilakukan terhadap banyak buku dan diperoleh berdasarkan catatan-catatan yang berhubungan dengan penelitian, selain itu peneliti mempergunakan data yang diproleh dari internet, jurnal, skripsi, dan lain-lain. 


\section{Tehnik Analisis Data}

Analisis data dilakukan dengan menggunakan tehnik analisis statistik dengan bantuan software komputer Microsoft Excel 2016 untuk input data, SPSS versi 16.0 for windows untuk melakukan pengujian korelasi rank spearman. Untuk mendapatkan keabsahan data yang diteliti maka dilakukan uji validitas, uji reliabilitas.

\section{Uji Validitas}

Uji validitas merupakan salah satu usaha penting yang harus dilakukan guna mengukur kevalidan dari instrumen. Validitas menunjukan sejumlah mana suatu alat ukur mampu mengukur apa yang ingin diukur (Sugiyono 2012). Kriteria pengukuran yang digunakan adalah:

a. Apabila $r$-hitung $>$ r-tabel dengan $d f=n-2$, maka kesimpulannya kuesioner tersebut valid.

b. Apabila $r$-hitung $<$ r-tabel dengan $\mathrm{df}=\mathrm{n}-2$, maka kesimpulan kuesioner tersebut tidak valid.

Keterangan: $\mathrm{n}=$ jumlah sampel dan $\mathrm{df}=0,10$

Rumus yang digunakan:

$$
r_{x y}=\frac{N \Sigma x y_{-\left(\sum x\right)}\left(\sum y\right)}{\sqrt{\left(N \Sigma x^{2}-\left(\sum x\right)^{2}\left(N \Sigma y^{2}-(\Sigma y)^{2}\right)\right.}}
$$

Keterangan:

$\mathrm{r}_{\mathrm{xy}} \quad=$ koefisien korelasi variabel $\mathrm{x}$ dan $\mathrm{y}$

$\mathrm{y} \quad=$ total skor

$\mathrm{x} \quad=$ skor variabel (jawaban responden)

$\mathrm{N} \quad=$ jumlah responden

\section{Uji Reliabilitas}

Reliabilitas bertujuan untuk mengetahui sejauh mana hasil pengukuran tetap konsisten, apabila dilakukan pengukuran secara berulang-ulang atau lebih terhadap gejala yang sama dengan menggunakan alat pengukuran yang sama pula. Hasil yang ditunjukan relatif sama walaupun terdapat perbedaan yang kecil, namun jika perbedaan cukup besar maka pengukuran tersebut dikatakan reliabel. Kriteria instrumen penelitian menurut Azwar, (2013) dikatakan reliabel, bila koefisien reliabilitasnya (r_11) > 0,6. Adapun rumus yang digunakan adalah rumus alpha cronbach dengan rumus:

$$
r_{11}=\left(\frac{n}{n-1}\right)\left(1-\frac{\sum \sigma_{t}^{2}}{\sigma_{t}^{2}}\right)
$$

Keterangan:

r_11 = Koefisien Reliabilitas Instrumen

$\mathrm{n} \quad=$ Jumlah Item Pertanyaan

$\Sigma \sigma_{-}{ }^{\wedge} 2=$ Jumlah Varians Butir

$\sigma_{-} \bar{t}^{\wedge} 2=$ Varians Total 


\section{Analisis Korelasi}

Tehnik pengujian yang digunakan dalam penelitian ini adalah uji korelasi rank spearman. Korelasi rank spearman merupakan suatu teknik analisis data dengan tujuan untuk menguji adanya hubungan antara variabel penting karena dengan mengetahui tingkat hubungan yang ada, peneliti akan mengembangkan sesuai dengan tujuan penelitian. Berikut adalah interval tingkat hubungan dalam analisis korelasi.

Tabel 1. Tingkat Hubungan Dalam Analisis Korelasi

\begin{tabular}{cc}
\hline Interval Koefisien & Tingkat Hubungan \\
\hline $0,00-0,19$ & Sengat Rendah \\
$0,20-0,39$ & Rendah \\
$0,40-0,59$ & Sedang \\
$0,60-0,79$ & Kuat \\
$0,80-1,00$ & Sangat Kuat \\
\hline Sumber: Sugiyono, 2013 &
\end{tabular}

\section{Uji t}

Uji t digunakan untuk menguji apakah ada hubungan secara parsial antara variabel bebas Harga (X1), Merek (X2), Threat Emotion (X3) dan Lokasi Penjualan (X4) dengan variabel terikat Loyalitas Konsumen $(\mathrm{Y})$. Uji t pada penelitian ini menggunakan program SPSS for windows 16,0 dengan cara membandingkan antara signifikansi hitungan masing-masing variabel bebas terhadap variabel terikat. Kriteria yang digunakan dalam penelitian ini untuk pengambilan keputusan pada taraf kepercayaan $95 \%$ atau taraf uji $\alpha=$ 0,05 yaitu dengan membandingkan antara t-hitung dengan t-tabel dengan pengujian sebagai berikut:

$$
t=r_{s} \sqrt{\frac{N-2}{1-r_{s}^{2}}}
$$

Keterangan:

rs = Koefisien Rank Spearman

$\mathrm{N} \quad=$ Jumlah Sampel

$\mathrm{T} \quad=\mathrm{t}$-hitung

Kriteria pengujian:

1. Dengan cara membandingkan nilai t_hitung dengan t_tabel

- Jika t_hitung>t_tabel maka terdapat hubungan yang signifikan

- Jika t_hitung<t_tabel maka tidak terdapat hubungan yang signifikan

2. Dengan cara menggunakan angka probabilitas signifikansi

- Apabila nilai signifikansi $\alpha<0,05$ maka berkorelasi signifikan

- Apabila nilai signifikansi $\alpha>0,05$ maka tidak berkorelasi signifikan.

\section{HASIL DAN PEMBAHASAN}

\section{Profil Responden}

Tabel 2 menunjukan bahwa responden yang mendominasi menurut jenis kelamin adalah responden laki-laki lebih dari 50\%, dengan usia responden pada rentang usia 20 24 tahun. Tingkat pendidikan responden yang paling banyak adalah lulusan Sekolah 
Lanjutan Tingkat Atas (SLTA). Sebagian besar dari responden yang diambil adalah masih bersatus sebagai pelajar.

Tabel 2. Karakteristik Responden

\begin{tabular}{lccc}
\hline No & Profil Responden & Frekuensi (Orang) & Persentase (\%) \\
\hline Jenis Kelamin & & \\
1 & Laki-Laki & 28 & 56 \\
2 & Perempuan & 22 & 44 \\
& Total & $\mathbf{1 0 0}$ & \\
& Usia (tahun) & & 28 \\
3 & $15-19$ & 14 & 44 \\
4 & $20-24$ & 22 & 16 \\
5 & $25-29$ & 8 & 4 \\
6 & $30-34$ & 2 & 4 \\
7 & $35-39$ & 2 & 2 \\
8 & $40-44$ & 1 & 2 \\
9 & $45-49$ & 1 & $\mathbf{1 0 0}$ \\
& Total & $\mathbf{5 0}$ & 6 \\
10 & & 3 & 50 \\
11 & Tingkat Pendidikan & 25 & 4 \\
12 & SLTP & 2 & 34 \\
13 & SLTA & 17 & 6 \\
14 & D3 & 3 & $\mathbf{1 0 0}$ \\
& S1 & $\mathbf{5 0}$ & \\
15 & S2 & & 56 \\
16 & Total & 28 & 32 \\
17 & Pekerjaan & 16 & 4 \\
18 & Pelajar & 4 & $\mathbf{1 0}$ \\
& Wira Swasta & 2 &
\end{tabular}

Sumber: Data primer, diolah 2019

\section{Uji Validitas}

Berdasarkan Tabel 3 menunjukkan hasil dari pengujian validitas dari masing-masing variabel yang mana meliputi variabel harga, merek, threat emosion dan lokasi penjualan dengan loyalitas konsumen yoghurt memory 84 . Diperoleh hasil uji validitas nilai koefisien korelasi lebih besar dari r-tabel, dengan $n$ sama dengan 50 pada tingkat kepercayaan $5 \%$; r-tabel $=2,278$ (koefisien korelasi $>2,278$ ). Dari hasil tersebut menunjukkan bahwa semua indikator variabel tersebut sudah valid. Hal ini berarti indikator yang digunakan mampu mampu mengukur apa yang seharusnya diukur pada setiap variabel atau bisa dilanjutkan untuk pengujian pada tahap selanjutnya.

\section{Uji Reliabilitas}

Berdasarkan Tabel 3, menunjukkan hasil uji reliabilitas bahwa semua indikator memenuhi kriteria reliabel. Hal ini ditunjukkan oleh nilai cronbach alpha secara keseluruhan indikator dari lima variabel mendapat nilai lebih dari 0,6 $(>0,6)$, berarti alat ukur (kuesioner) yang dipakai dipercaya atau reliabel. 
Tabel 3. Hasil Uji Validitas dan Reliabilitas

\begin{tabular}{|c|c|c|c|c|}
\hline Variabel Penelitian & Item & r-hitung & $\begin{array}{l}\text { r-tabel } \\
(5 \%)\end{array}$ & $\begin{array}{l}\text { Cranbach } \\
\text { Alpha }\end{array}$ \\
\hline \multirow[t]{5}{*}{ Harga $(\mathrm{X} 1)$} & $\mathrm{X} 1.1$ & 0,650 & 0,278 & 0,767 \\
\hline & $\mathrm{X} 1.2$ & 0,659 & 0,278 & \\
\hline & X1.3 & 0,767 & 0,278 & \\
\hline & X1.4 & 0,767 & 0,278 & \\
\hline & $\times 1.5$ & 0,751 & 0,278 & \\
\hline \multirow[t]{5}{*}{ Merek (X2) } & $\mathrm{X} 2.1$ & 0,642 & 0,278 & 0,688 \\
\hline & $\mathrm{X} 2.2$ & 0,623 & 0,278 & \\
\hline & $\mathrm{X} 2.3$ & 0,719 & 0,278 & \\
\hline & $\mathrm{X} 2.4$ & 0,708 & 0,278 & \\
\hline & $\mathrm{X} 2.5$ & 0,675 & 0,278 & \\
\hline \multirow[t]{5}{*}{ Threat Emotion (X3) } & $\mathrm{X} 3.1$ & 0,769 & 0,278 & 0,816 \\
\hline & X3.2 & 0,781 & 0,278 & \\
\hline & X3.3 & 0,731 & 0,278 & \\
\hline & X3.4 & 0,770 & 0,278 & \\
\hline & $\times 3.5$ & 0,766 & 0,278 & \\
\hline \multirow[t]{5}{*}{ Lokasi Penjualan (X4) } & $\mathrm{X} 4.1$ & 0,314 & 0,278 & 0,634 \\
\hline & $\mathrm{X} 4.2$ & 0,760 & 0,278 & \\
\hline & X4.3 & 0,733 & 0,278 & \\
\hline & X4.4 & 0,745 & 0,278 & \\
\hline & $\times 4.5$ & 0,700 & 0,278 & \\
\hline \multirow{8}{*}{$\begin{array}{l}\text { Loyalitas } \\
\text { (Y) }\end{array}$} & $\mathrm{Y} 1.1$ & 0,821 & 0,278 & 0,867 \\
\hline & $\mathrm{Y} 1.2$ & 0,781 & 0,278 & \\
\hline & Y1.3 & 0,734 & 0,278 & \\
\hline & Y1.4 & 0,662 & 0,278 & \\
\hline & Y1.5 & 0,577 & 0,278 & \\
\hline & Y1.6 & 0,821 & 0,278 & \\
\hline & Y1.7 & 0,729 & 0,278 & \\
\hline & Y1.8 & 0,670 & 0,278 & \\
\hline
\end{tabular}

Sumber: Data primer, diolah 2019

Hasil Analisis Hubungan Harga (X1), Merek (X2), Threat Emotion (X3) dan Lokasi Penjualan (X4) Dengan Loyalitas Konsumen (Y)

Hubungan Antara Harga, Merek, Threat Emotion dan Lokasi Penjualan Dengan Loyalitas Konsumen Yoghurt Memory 84 di Kota Salatiga dapat di ketahui melalui uji korelasi Rank Spearman (r). Hasil penelitian melalui korelasi Rank Spearman terhadap masing-masing variabel penelitian ditunjukkan pada Tabel 4.

Tabel 4. Hasil Analisis Korelasi Rank Spearman

\begin{tabular}{|c|c|c|c|c|c|c|}
\hline Variabel & $\begin{array}{c}\text { Koefesien } \\
\text { Korelasi }\end{array}$ & Sig & t-hitung & t-tabel & Keterangan & $\begin{array}{c}\text { Tingkat } \\
\text { Hubungan }\end{array}$ \\
\hline Harga (X1) & $0,874\left({ }^{\star \star}\right)$ & 0,000 & 12,45 & 1,67 & Signifikan & Sangat Kuat \\
\hline Merek (X2) & $0,351\left(^{*}\right)$ & 0,012 & 2,59 & 1,67 & Signifikan & Rendah \\
\hline Threat Emotion (X3) & $0,595\left(^{* \star}\right)$ & 0,000 & 5,12 & 1,67 & Signifikan & Sedang \\
\hline $\begin{array}{l}\text { Lokasi Penjualan } \\
\text { (X4) }\end{array}$ & $0,793\left(^{\star \star *}\right)$ & 0,000 & 9,01 & 1,67 & Signifikan & Kuat \\
\hline
\end{tabular}

Tabel 4 menunjukkan hasil dari analisis korelasi Rank Spearman bahwa variabel harga, merek, threat emotion dan lokasi penjualan yang digunakan dalam penelitian ini 
terdapat hubungan yang signifikan terhadap loyalitas konsumen dengan nilai error dibawah 0,05 .

\section{Hubungan Antara Harga Dengan Loyalitas Konsumen}

Variabel X1 yakni harga dari hasil uji analisis korelasi rank spearman memiliki nilai koefisien korelasi sebesar 0,874 dengan nilai t-hitung $(12,45)>$ t-tabel $(1,67)$ dan signifikansi $0,000<0,05$. Sesuai dengan hasil uji analisis korelasi Rank Spearman membuktikan bahwa harga produk yoghurt memory 84 di Kota Salatiga memiliki hubungan yang signifikan terhadap loyalitas konsumen. Hasil penelitian ini sejalan dengan penelitian yang dilakukan oleh Nurullaili dan Wijayanto (2013), menyatakan harga yang wajar akan menjadi keputusan bagi konsumen untuk tetap setia pada produk tersebut. Di yoghurt memory 84 harga yang di tawarkan oleh pihak pengelola menysuaikan kebutuhan konsumen dan dapat dilihat sebagai berikut:

1. Smoothies Rp 12.000,- /gelas

2. Yoghurt Rp $8.000,-/$ botol

3. Es Lilin Rp 2.000,-

Harga yang di tawarkan pihak pengelola sudah termasuk beberapa varian rasa seperti coklat, durian, jeruk, lychee, red velvet, strawberry, vanilla, lutty frutty. Konsumen beranggapan bahwa harga-harga yang ditawarkan oleh pihak pengelola yoghurt memory 84 sudah terjangkau baik untuk kalangan masyarakat ekonomi bawah, menengah sampai ekonomi atas. Hal tersebut membuat konsumen merasa senang dan loyal untuk datang kembali membeli yoghurt memory 84 .

\section{Hubungan Antara Merek Dengan Loyalitas Konsumen}

Variabel X2 yakni Merek dari hasil uji analisis korelasi rank spearman memiliki nilai koefisien korelasi sebesar 0,351 dengan nilai t-hitung $(2,59)>t$-tabel $(1,67)$ dengan nilai signifikansi 0,012 dimana kecil dari 0,05. Sesuai dengan hasil uji analisis korelasi rank spearman membuktikan bahwa merek produk yoghurt memory 84 di Kota Salatiga memiliki hubungan yang signifikan dengan loyalitas konsumen. Hasil penelitian ini sejalan dengan penelitian yang dilakukan oleh Widodo dan Tresna (2018) menyatakan komitmen yang mendalam untuk melakukan pembelian ulang produk atau jasa yang terjadi preferensinya secara konsisten dengan cara membeli ulang merek yang sama meskipun ada pengaruh situasional yang dapat menimbulkan perilaku peralihan.

Yoghurt Memory 84 adalah salah satu merek susu fermentasi yang di olah sendiri oleh pihak pengelola caffe dan diberi label sebelum di pasarkan atau dijual kekonsumen yang ada di Kota Salatiga dan sekitarnya. Selain itu pihak pengelola yoghurt memory 84 juga melakukan promosi melalui media sosial tujuannya supaya konsumen tahu mengenai susu fermentasi dengan ciri khas rasa merek yoghurt memory 84 yang mana berbeda dari produk susu fermentasi lainnya.

\section{Hubungan Antara Threat Emotion Dengan Loyalitas Konsumen}

Variabel X3 yakni Threat Emotion atau peresaan terancam terbukti memiliki hubungan dengan loyalitas konsumen Yoghurt Memory 84. Hal ini dilihat hasil uji analisis korelasi rank spearman nilai koefisien korelasi sebesar 0,595 dengan t-hitung $(5,12)>$ ttabel $(1,67)$ dan signifikan $0,000<0,05$. Sesuai dengan hasil uji analisis korelasi rank spearman membuktikan bahwa variabel Threat Emotion berkorelasi signifikan terhadap variabel loyalitas konsumen. Hasil penelitian ini Sejalan dengan penelitian yang dilakukan oleh Ferrinadewi (2008); Passyn dan Sujan (2006), emosi negatif seperti rasa takut dibutuhkan untuk menarik perhartian konsumen dan mengisyaratkan adanya ancaman yang mungkin dihadapi konsumen dan hal ini akan mengarahkan konsumen untuk mencari solusinya dalam hal ini adalah keputusan membeli produk dan merek pilihannya.

Susu fermentasi yoghurt memory 84 memiliki keunggulan rasa asam yang pas, sangat baik untuk pencernaan dan juga memiliki banyak varian rasa yang di sediakan 
oleh pihak pengelola, bukan hanya itu saja yoghurt memory 84 sudah mempunyai sertifikasi halal untuk menjamin konsumen bahwa produk yang di konsumsi aman. Hal ini membuat konsumen percaya bahwa produk susu fermentasi yang mereka konsumsi aman dan baik untuk kesehatan.

\section{Hubungan Antara Lokasi Penjualan Dengan Loyalitas Konsumen}

Variabel X4 yakni lokasi penjualan dari hasil uji analisis korelasi rank spearman memiliki nilai koefisien korelasi sebesar 0,793 dengan t-hitung $(9,01)>t$-tabel $(1,67)$ dan signifikansi $0,000<0,05$. Sesuai dengan hasil uji analisis korelasi rank spearman membuktikan bahwa lokasi penjualan produk yoghurt memory 84 di Kota Salatiga memiliki hubungan yang signifikan terhadap loyalitas konsumen. Hasil penelitian ini sejalan dengan penelitian yang dilakukan oleh Wulan dan Susanto (2013) menyatakan lokasi yang tepat dan strategis memudahkan akses bagi calon konsumen untuk mepengaruhi kebutuhannya dan akan memberi sebuah keuntungan tersendiri bagi sebuah untuk secara tidak langsung mempengaruhi keputusan pembelian konsumen.

Lokasi penjualan yoghurt memory 84 strategis tidak jauh dari pemukiman masyarakat atau perumahan dan juga lokasi penjualan tidak jauh dari pusat Kota Salatiga. Hal ini memberikan dampak positif bagi keberlangsungan suatu usaha yang dijalankan oleh pihak pengelola caffe, serta tempat yang disediakan aman dan nyaman jauh dari polusi kendaraan lalu lintas, halaman parkir luas, kebersihan tempat terjaga, pelayanan yang memuaskan hal tersebut sangat cocok untuk konsumen bersantai dan menikmati susu yoghurt yang disediakan oleh pihak pengelola caffe.

\section{SIMPULAN}

Berdasarkan hasil penelitian dan pembahasan di atas, maka dapat disimpulkan bahwa variabel harga (X1), merek (X2), threat emotion (X3), dan lokasi penjualan (X4) memiliki tingkat hubungan yang positif serta berkorelasi signifikan dengan loyalitas konsumen $(Y)$. Hubungan dari setiap variabel bebas $(X)$ dengan loyalitas konsumen $(Y)$ memiliki tingkatan yang berbeda-beda antara lain: Harga memiliki tingkat hubungan yang sangat kuat, merek memiliki tingkat hubungan yang rendah, Threat Emotion memiliki tingkat hubungan yang sedang, dan lokasi penjualan memiliki tingkat hubungan yang kuat, sehingga dari hasil ini Yoghurt Memory 84 perlu memperhatikan variabel-variabel tersebut, terutama variabel harga produk dan penentuan lokasi penjualan untuk menciptakan serta meningkatkan loyalitas konsumen.

\section{DAFTAR PUSTAKA}

Aldi, A. 2012. Pengaruh Citra Merk dan Kualitas Produk Terhadap Keputusan Pembelian Konsumen. Yogyakarta: Universitas Negeri Yogyakarta.

Azwar, S. 2013. Sikap Manusia: Teori dan Pengukurannya. Yogyakarta: Pustaka Pelajar.

Ferrinadewi, E. 2008. Pengaruh Threat Emotion Konsumen Dan Brand Trust Pada Keputusan Pembelian Produk Susu Anlene di Surabaya. Jurnal Kewirausahaan, 1(2), HIm. 1-8.

Hiscock, Russell. 2001. Most trusted brands. Marketing 3(1): 32-33.

Kotler, Philip dan Keller, Kevin Lane. 2009. Manajemen Pemasaran, Edisi 13 Jilid 1. Jakarta: Erlangga.

Kotler, Philip, \& Gary Amstrong. 2014. Principle of Marketing. Edisi 15. Harlow: Pearson Education

Notoatmodjo, S. 2010. Metodologi Penelitian Kesehatan. Rineka Cipta. Jakarta. 
Nurullaili, N., \& Wijayanto, A. 2013. Analisis Faktor-Faktor yang memengaruhi Loyalitas Konsumen Tupperware (Studi Pada Konsumen Tupperware di Universitas Diponegoro). Jurnal Administrasi Bisnis, 2(1).

Passyn, Kirsten \& Mita Sujan. 2006. "Self-Accountability Emotions and Fear Appeals: Motivating Behavior". Journal of Consumer Psychology, Vol. 32, p. 583-590

Shafa, M. R., Rozza, S., \& Marbun, J. 2016. Pengaruh Strategi Positioning Pada Tabungan Faedah BRI Syariah iB Terhadap Loyalitas Pelanggan. Politeknik Negeri Jakarta. 432-437

Sugiyono. 2012. Metode Penelitian Kuantitatif Kualitatif dan R\&D. Alfabeta. Bandung

Sugiyono 2013. Metode Penelitian Pendidikan Pendekatan Kuantitatif, Kualitatif, dan $R \& D$. Bandung: Alfabeta.

Tamime dan R.K. Robinson. 2007. Yoghurt Science and Technology. Third Edition. Woodhead Publishing. Cambridge.

Widodo, T. H., \& Tresna, P. W. 2018. Pengaruh Kepercayaan Merek Terhadap Loyalitas Merek (Studi Pada Pengguna Kartu As Di STIA YPPT Priatim Tasikmalaya). AdBispreneur: Jurnal Pemikiran dan Penelitian Administrasi Bisnis dan Kewirausahaan, 3(1), 81-88.

Wulan, S., \& Susanto, F. 2013. Hubungan persepsi konsumen tentang lokasi usaha dengan keputusan pembelian pada UD Sinar Fajar Cabang Antasari di Bandar Lampung. Jurnal Manajemen dan Bisnis, 4(1).

Yuliani. 2010. Analisis Pengaruh Lokasi, Promosi dan Kualitas Pelayanan Terhadap Keputusan (Studi Pada Penggunan Kartu Prabayar CDMA Flexi Trendy di Desa Krebet Senggrong Kecamatan Bululawang Kabupaten Malang). Karya IImiah Malang: Universitas Negeri Malang. 